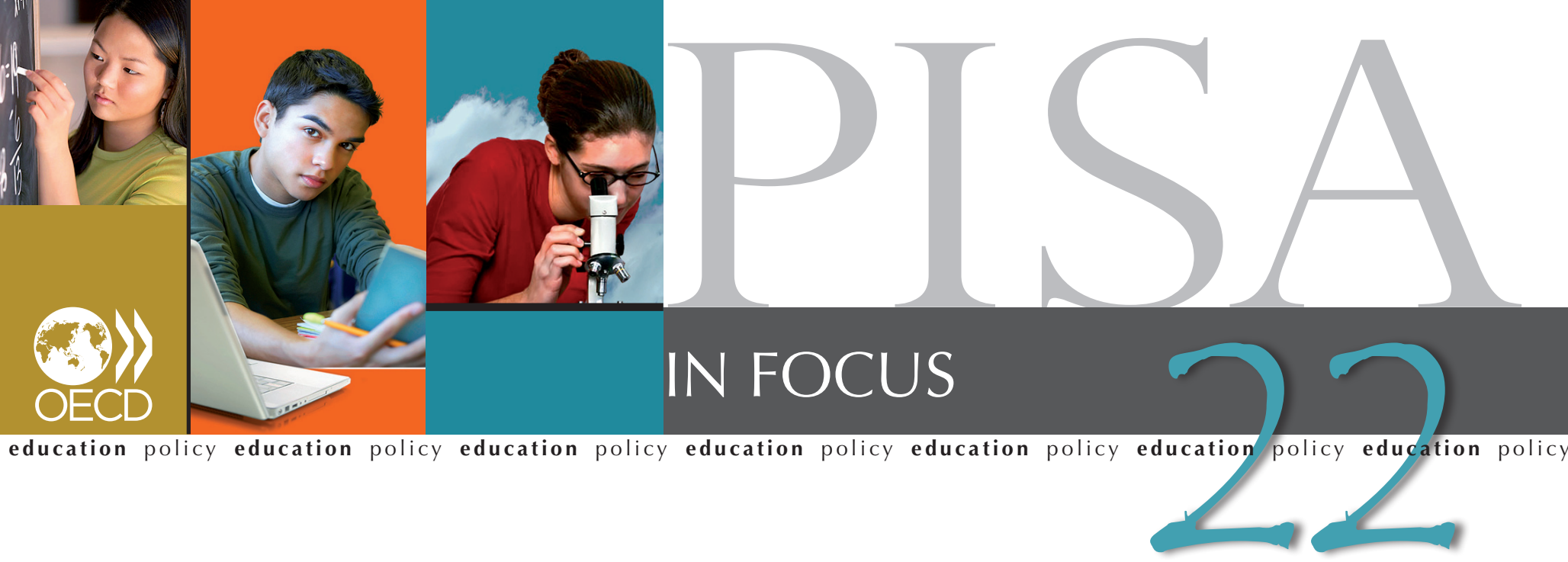

\title{
How do immigrant students fare in disadvantaged schools?
}

- Immigrant students often have to overcome multiple barriers at once in order to succeed at school.

- Across most OECD countries, poor performance among immigrant students relative to other students is strongly related to social disadvantage at school, as reflected in the proportion of students whose mothers have low levels of education.

- The concentration, in a school, of immigrant students or of those who do not speak the language of instruction at home is not as strongly related to poor performance.

The policies and practices chosen to integrate immigrant students into school systems - and societies - provoke strong reactions and contentious debates. Does a high concentration of immigrant students who do not speak the language of instruction at home affect school outcomes for those students and their peers? How are the variations in performance between immigrant and non-immigrant students related to differences in the socio-economic intake of the schools they attend?

Immigrant students face multiple challenges to learning...
Disadvantage and immigrant status are closely linked. Most immigrants leave their home countries in search of better economic prospects. Once immigrants arrive in a host country, they often settle in communities where there are other immigrants who share their culture, their language and often their socio-economic status. Immigrants are often employed in lower-paying jobs and have limited borrowing opportunities, thus they often have fewer housing choices. Their children often attend the same schools - and those schools frequently have large proportions of immigrant students. As a result, immigrant students are not evenly distributed across schools; in fact, they tend to be concentrated in certain schools. In most cases, these schools have relatively large populations of immigrants and are generally more socio-economically deprived than other schools. As a result, immigrant students often have to overcome multiple barriers at once in order to succeed at school: a language barrier, their own immigrant status, a disadvantaged background - and the fact that many of their classmates are struggling to surmount these same obstacles to success at school.

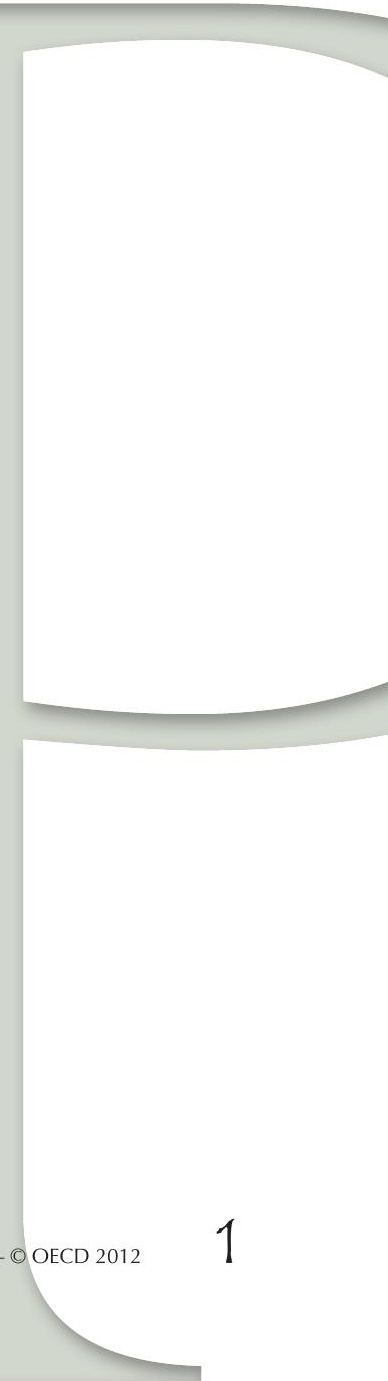


Disentangling the multiple challenges immigrant students face Proportion of all immigrant students who attend the quarter of schools with the highest proportion of ...

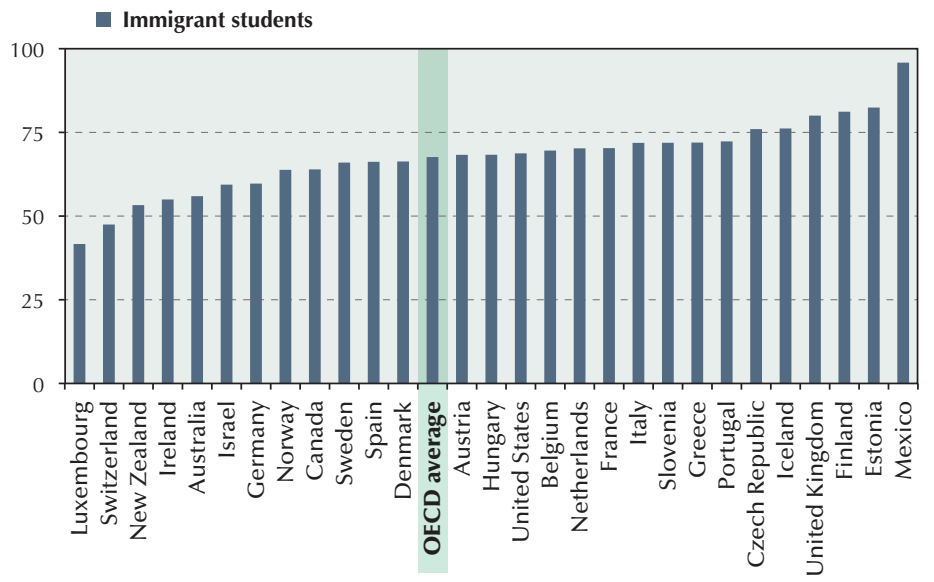

- Immigrant students who do not speak the language of instruction at home

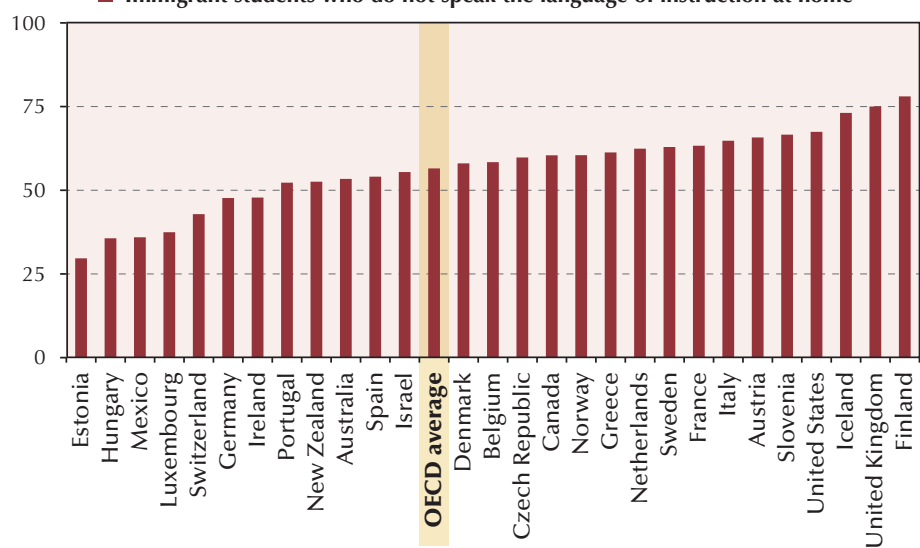

a Students with low-educated mothers (less than upper secondary education)

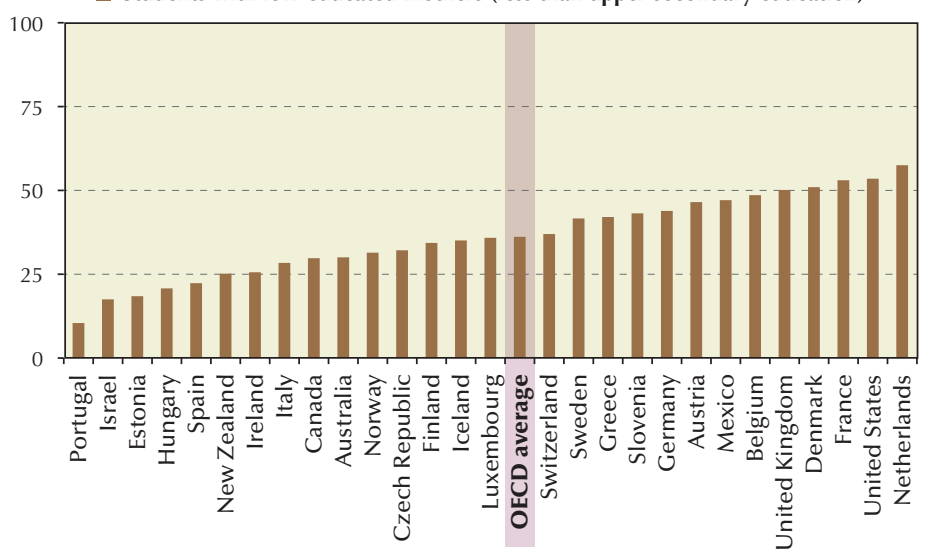

Note: Countries are ranked in ascending order for each measure of concentration. Source: OECD (2012), Untapped Skills: Realising the Potential of Immigrant Students, Figure 5.8 and Table 5.4.
Disentangling the relationship among immigrant status, language skills and socio-economic background is not straightforward. However, PISA data show how these three elements are interrelated and how they are associated with student performance at school.

... one of which is related to the profile of the school they attend.

An analysis of data from PISA 2009 focused on three types of schools: those with the highest concentrations of immigrant students, those with the highest concentration of immigrant students who speak a different language at home than the language of instruction at school, and those with the highest concentration of students whose mothers have low levels of education. Having a low-educated mother, that is, a mother who has not attained a secondary education, is a measure of socio-economic disadvantage particularly relevant among immigrant populations.

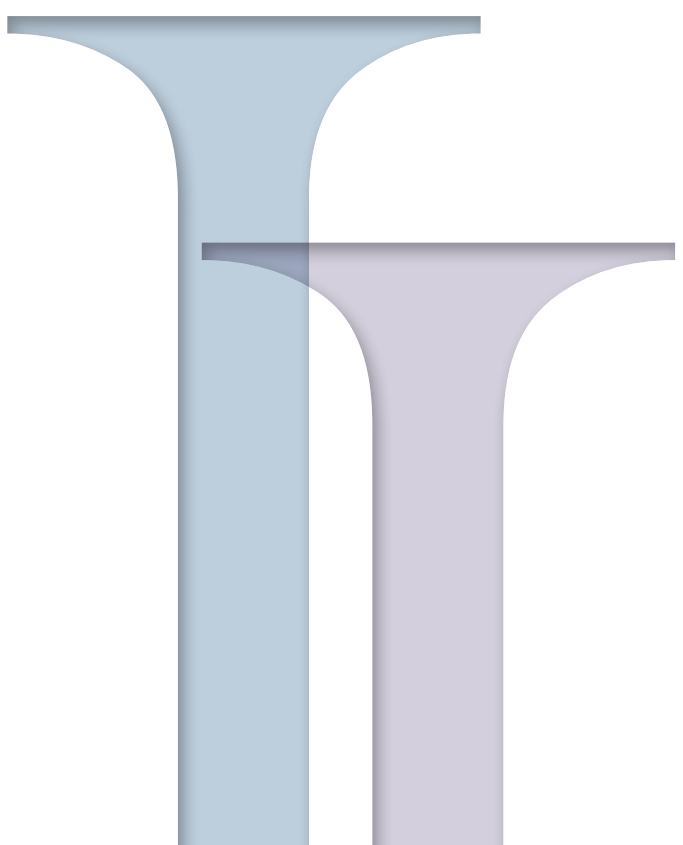




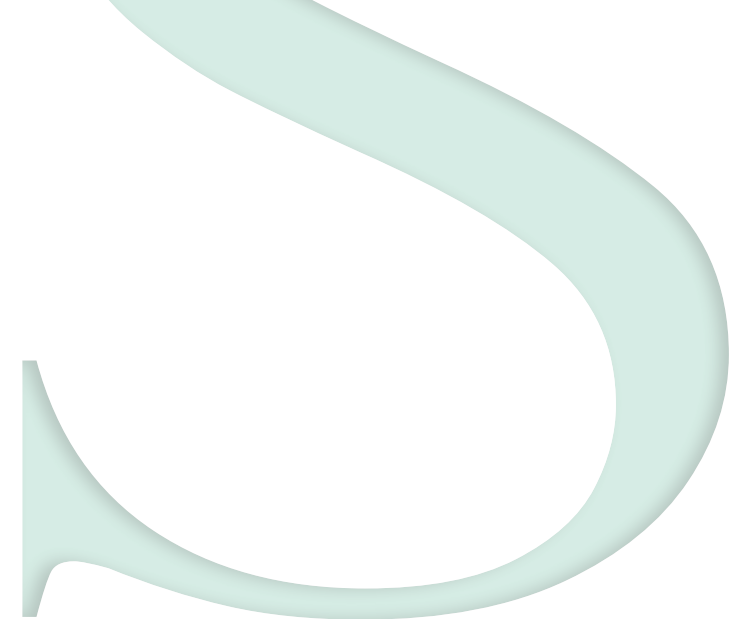

Countries vary markedly in how immigrant students are accommodated in schools. In New Zealand, for example, $50 \%$ of immigrant students - well below the OECD average of $68 \%$ - attend a school that has a large proportion of immigrant students. In addition, the concentration of immigrant students in socio-economically disadvantaged schools is also relatively low in New Zealand: only one in four immigrant students - compared with the OECD average of $36 \%$ - attends a school that has a large proportion of students whose mothers have low levels of education. In Germany, the concentration of immigrant students in schools is moderate, around the OECD average, while the concentration of immigrant students in socio-economically disadvantaged schools is

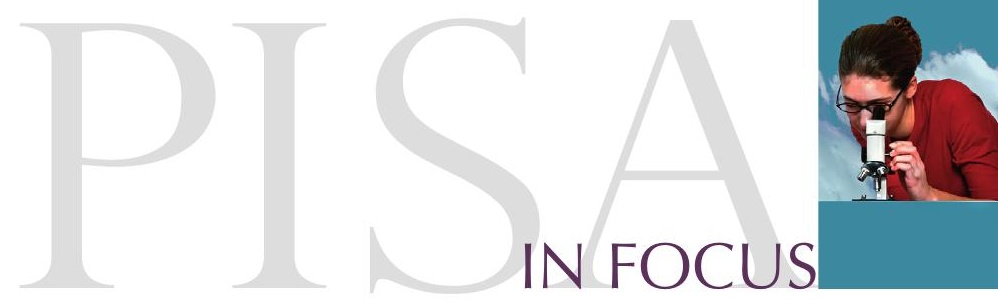

higher than the OECD average. In the United Kingdom, high concentrations of immigrant students in schools are coupled with high concentrations of immigrant students in the most disadvantaged schools.

When analysing student performance through this prism, poor student performance, particularly among immigrant students, is most strongly related to the proportion of students in a school whose mothers have low levels of education. This finding indicates that immigrant students - indeed all students - face a major obstacle to success at school when they are concentrated in schools attended by students who face similar socio-economic disadvantage.

High concentrations of disadvantage in schools are strongly related to poor reading performance among immigrant students

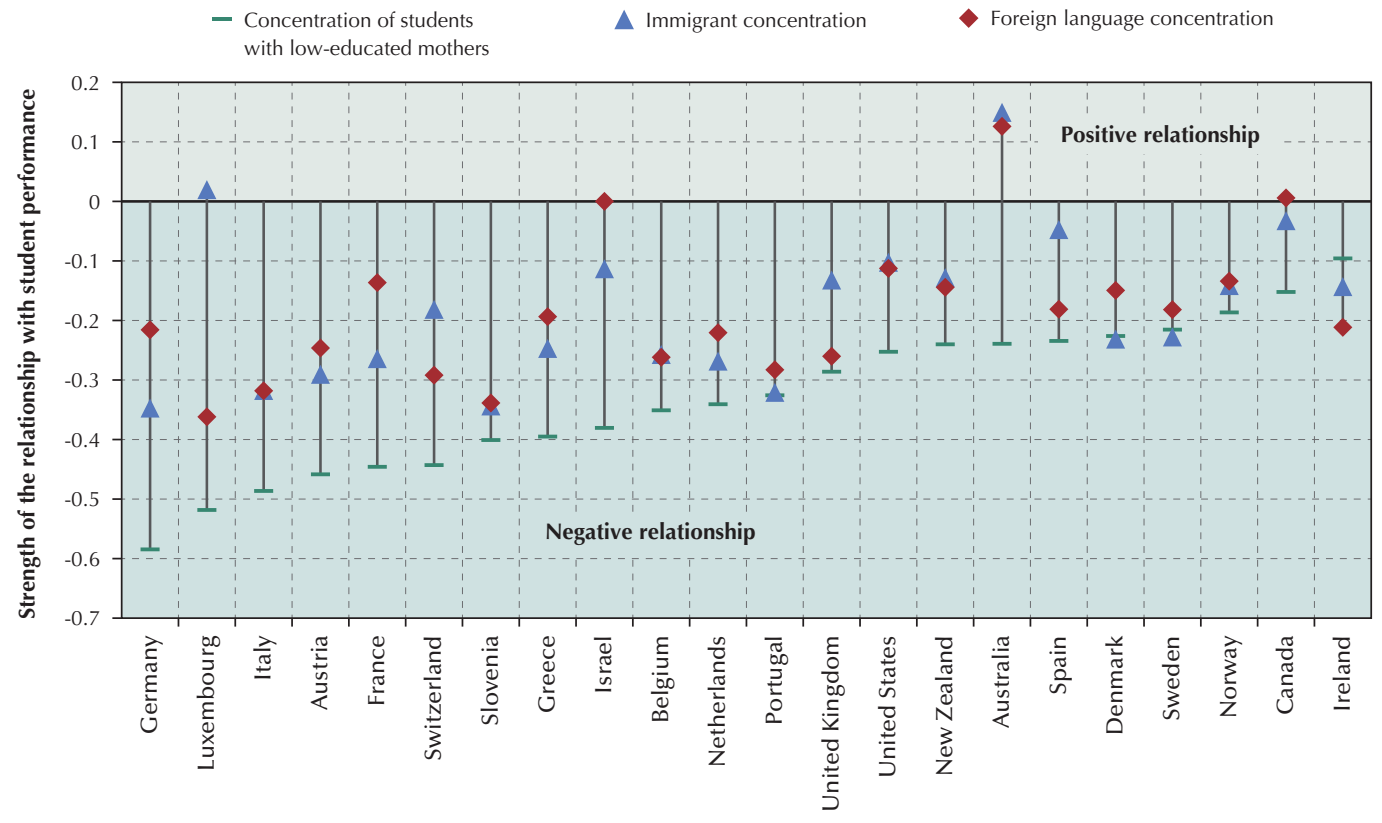

Note: Countries are ranked in ascending order of the strength of the relationship between student performance and the concentration of students, in individual schools, with low-educated mothers.

Source: OECD (2012), Untapped Skills: Realising the Potential of Immigrant Students, Figure 5.9 and Table 5.6. 
In contrast, the results suggest that it is not the proportion of immigrant students or the proportion of those who speak a different language that is most strongly associated with poor performance. In other words, being in a school with students from different countries or who speak multiple languages does not hinder learning as much as being in a school that has a high concentration of disadvantaged students does, as measured by the proportion of students who have mothers with low levels of education. In fact, there are many high-achieving schools that have large proportions of immigrant students. Often, that high performance is the result of specific national or regional education policies designed to accommodate - and make the most of heterogeneous student populations.
Many schools in the Canadian province of Alberta, for example, have just this kind of profile. Immigration policies that, for example, target highly educated individuals can also raise performance levels in schools. In other cases, certain high-performing private schools specifically select students from other countries and offer internationally recognised curricula.

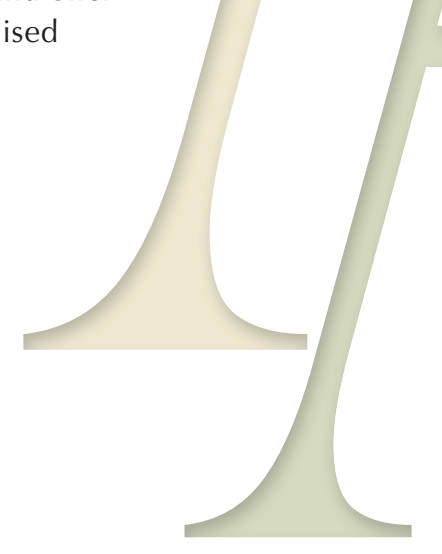

The bottom line: Student performance is not necessarily hindered by the concentration of immigrants in a school or class. But the concentration of socio-economic disadvantage in a school is strongly associated with poor student performance. Reducing the concentration of disadvantage in individual schools is thus a good first step towards helping immigrant students integrate successfully into school and, ultimately, society.

\section{For more information}

Contact Pablo Zoido (Pablo.Zoido@oecd.org)

See OECD (2012), Untapped Skills: Realising the Potential of Immigrant Students, OECD Publishing and the full set of related tables.

\section{Visit}

www.pisa.oecd.org www.oecd.org/pisa/infocus
Coming next month

What do students expect to do after finishing upper secondary school? 